\title{
UM ESTUDO SOBRE ALEITAMENTO MATERNO ****
}

\author{
Malvina de Oliveira Ramos Netto* \\ Maria Jacyra de Campos Nogueira ** \\ Eloisa Aparecida Guedes ***
}

RAMOS NETTO, M. O. et al. - Um estudo sobre aleitamento materno. Rev. Esc. Enf. USP, 12(2):77-100, 1978.

Os autores tecem introdutoriamente considerações sobre as vantagens do aleitamento humano e descrevem as causas sócio-econômicas que estão influenciando no mundo, o abandono dessa prática. Em seguida descrevem e comentam os résultados de uma pesquisa realizada com um grupo de mães e que teve como objetivo, estudar alguns aspectos relativos ao aleitamento de seus filhos.

\section{INTRODUÇÃO}

A promoção e proteção da saúde do indivíduo, começa desde o momento da fecundação. Posteriormente, a saúde do feto e da criança, principalmente no primeiro ano de vida, tem uma dependência muito grande da mãe e do meio ambiente em que ambos vivem. Esta

- Professor Assistente da disciplina Enfermagem de Saúde Pública da EEUSP.

* Professor Assistente Doutor da disciplina Enfermagem de Saúde Pública da EEUSP.

*** Auxiliar de Ensino da disciplina Enfermagem de Saúde Pública da EEUSP.

**** Este trabalho foi realizado com a colaboração dos seguintes alunos eursando Habilitação em Enfermagem de Saúde Pública da Escola de Enfermagem da USP: Adélia Ono, Angela Maria Martins Costa, Angela Maria Rosin Tachini, Eliana Granato Valin, Maria Helena Faria, Maria Helena Pereira Sant'Ana, Neide Miyako Hasegawa, Nildete Vieira Nunes, Sonia Regina Leite, Tania Regina Storto Moleiro e Walkiria Palota. 
é a razão pela qual os problemas de saúde relativos à maternidade e à infância, não podem ser estudados e atendidos separadamente e nem deixados de ser considerados como fundamentalmente sociais..$^{13}$

As condições sanitárias, econômicas e culturais têm uma estreita relação com a saúde do binômio mãe e filho, tal como sucede com cada um dos indivíduos que compõe a população. Entretanto, no caso da mãe e da criança há algo diferente, pois as mães estão expostas, ainda, aos riscos inerentes à gravidez, parto, puerpério e lactação e as crianças, às dificuldades do crescimento, do desenvolvimento e rao fato de que os riscos ambientais gerais se agravam para eles, devido à extrema labilidade do seu organismo em formação. ${ }^{13}$

Nos países menos desenvolvidos, os programas de assistência à mãe e à criança são prioritários, não só por ser a saúde uma manifestação de processo de adaptação física, biológica e social do homem, ao seu meio ambiente mas por ser a maternidade e a infância as épocas da vida mais oportunas para desenvolver essa adaptabilidade. Também, por motivos quantitativos, nesses mesmos países, os riscos da maternidade e da infância afetam um grupo considerável da população. Por exemplo, na América Latina, a população em torno de $1965^{13}$ estava constituída da seguinte forma: $16,6 \%$ de crianças de 0 a 4 anos; $25,7 \%$ de crianças de 5 a 14 anos; $18,3 \%$ de individuos de 15 a 24 anos; $23,8 \%$ de 25 a 44 anos; $12,2 \%$ de 45 a 64 e somente $3,4 \%$ de indivíduos com mais de 65 anos de idade. No Brasil, em $1970^{2}$, a população de crianças tinha aproximadamente, a seguinte distribuição: $14,7 \%$ pertencentes à faixa etária de 0 a 4 anos; $14,6 \%$ à faixa de 5 a 9 anos e $12,7 \%$ à de 10 a 14 anos, perfazendo um total de $42,0 \%$ de indivíduos menores de 14 anos existentes na população total.

Um estudo realizado em uma favela da Região da Grande São Paulo ${ }^{9}$, a qual podemos considerar, pelas características sócio-econômicas, uma pequena comunidade com características de regióes menos desenvolvidas, a população de menores de 12 anos, estava distribuída da seguinte maneira: 3,5\% eram menores de 1 ano; 7,9\% de 1 a 4 anos; $11,4 \%$ de 4 a 7 anos e 20,8\% de 7 a 12 anos, perfazendo um total de $43,6 \%$ de crianças menores de 12 anos, no total da população.

Por outro lado, as estatísticas existentes demonstraram que ${ }^{11}$ nesses países menos desenvolvidos, a mortalidade infantil é ele- 
vada, ao contrário do que acontece nos mais desenvolvidos. Por exemplo, o coeficiente de mortalidade infantil, em torno de 1973, na cidade de São Paulo, era de $65,1 \%$ e, em Recife, $91,2 \%$, enquanto que em São Francisco, nos Estados Unidos, era de $18,0 \%$ e em Sherbrooke, no Canadá, de $18,3 \%$.

Os problemas específicos que afetam a mãe e a criança, se agravam consideravelmente também, nos países menos desenvolvidos, não só porque a natalidade e a proporção de população infantil é maior mas, porque os riscos são maiores. Nestes países, as enfermidades transmissíveis e a desnutrição matam um grande número de crianças entre o $1 .^{\circ}$ e o $4 .^{\circ}$ ano de vida ${ }^{13}$.

De acordo com os resultados dos estudos realizados pela Investigação Interamericana de Mortalidade na Infância ${ }^{11}$, a deficiência nutricional foi o problema mais grave manifestado e a mortalidade por esta causa alcançou o seu ponto máximo, no primeiro ano de vida. Um aspecto importante visualizado por esse mesmo estudo, foi a relação existente entre a alimentação ao seio e a mortalidade infantil. Entre as crianças amamentadas com leite materno, as proporções de mortes devidas às enfermidades diarréicas e deficiência nutricional, foram mais baixas que entre as que nunca tinham sido amamentadas. Por outro lado, o número de crianças que faleceram no período pós-natal, poucas haviam sido alimentadas ao seio durante um mês ou mais; assim mesmo, somente $18,4 \%$ das falecidas na idade entre 6 e 11 meses, haviam recebido esta alimentação durante seis meses ou mais. Em São Paulo a proporção de crianças amamentadas durante um mês ou mais foi de somente $35,5 \%$.

E sabido ${ }^{7,13}$ que a alimentação é o aspecto mais importante da puericultura, porque o crescimento que tem o lactente, depende quase que exclusivamente dela, o que não acontece tanto em outras etapas da vida. $O$ metabolismo do lactente se caracteriza por exigências maiores de elementos nutritivos, em comparação com as do adulto e qualquer alteração na proporção dos componentes nutritivos se traduz, rapidamente, em fenômenos patológicos.

Há uma ação recíproca entre alimentação e infecção. A má alimentação aumenta a suscetibilidade à infecção e esta atinge severamente a nutrição formando um círculo vicioso de má saúde que culmina em uma desnutrição fatal ${ }^{5}$. 
A melhor forma de alimentar o lactente 7,13 é proporcionar-lhe alimentação natural ou materna, não só porque o leite de peito contém, de maneira equilibrada, elementos nutritivos importantes para o seu crescimento, mas porque é isento de impurezas e ainda, na amamentação, a criança estabelece relações emocionais com a mãe que são tão importantes para o seu desenvolvimento global. -

O leite humano satisfaz às necessidades nutritivas para o crescimento do bebê até a idade de 6 meses, aproximadamente. Estudos realizados ${ }^{5}$, têm demonstrado que crianças alimentadas ao peito perdem menos peso depois de nascer que as alimentadas artificialmente. Na realidade, a lactação prevê um mecanismo homeostático natural e, por outro lado, o leite humano possui uma combinação ótima de elêmentos nutritivos enquanto que os alimentos artificiais, não a possuem e requerem diluições ou modificações. Por exemplo, o leite de vaca contém quantidades excessivas de substâncias solúveis como sódio, potássio, cálcio, magnésio e fósforo que podem ser prejudiciais para a saúde do bebê. Associa-se também o alto conteúdo de gordura do leite de vaca, à obesidade infantil e a sua proteína estranha e aos cereais que geralmente são adicionados às fórmulas lácteas, as alergias e abstipações intestinais infantis.

Os preparados artificiais, por outro lado, podem ser adequados, para a alimentação do bebê mas, em grupos pobres, a falta de conhecimentos científicos e as limitações econômicas, podem induzir a mãe a utilizar alimentos artificiais inadequados ou insuficientes que não satisfazem as necessidades de crescimento da criança. Como o custo dos alimentos artificiais é muito elevado, podendo chegar de 40 a $60 \%$ do salário mínimo de alguns países, não é surpreendente que, com frequiência, muitas mulheres recorram a alimentos que contêm muito carboidrato e que podem assemelhar-se ao leite, quanto à cor e consistência mas, nunca, ao seu valor nutritivo. Este mesmo custo elevado pode, ainda, induzir as mães a utilizar os preparados mais caros, de forma excessivamente diluida 5 .

Alimentar o bebê ao seio tem, ainda, um papel importante na prevenção das infecções na criança; o colostro produzido durante as primeiras etapas da lactação, proporciona anticorpos maternos que protegem o bebê de muitas enfermidades. $O$ leite humano, ainda, 
faz com que as defecações das crianças sejam mais ácidas, o que impede $o$ crescimento de organismos intestinais patogênicos. Contudo, o fator mais importante associado ao leite materno é que há menos risco de contaminação bacteriana, pois embora o leite humano possa não ser estéril, raras vezes contém organismos patogênicos, enquanto que os alimentos artificiais frequientemente se contaminam durante o preparo e o armazenamento ${ }^{5}$.

Se nas sociedades prósperas é difícil manter a higiene que os alimentos artificiais requerem para que sejam seguros, nas sociedades pobres, a higiene inadequada, a falta de meios e a ignorância se combinam para impossibilitar a manutenção dos alimentos artificiais em condições adequadas de higiene. Há evidência clara que as infecções intestinais suaves são menos frequientes e menos severas entre os bebês alimentados ao peito que entre os alimentados com dietas artificiais, bem como certas infecções respiratórias e do ouvido ${ }^{5}$.

E evidente que, em certas ocasiões, o aleitamento materno é quase impossível, devido a problemas da mãe, tais como a lactação insuficiente, mamilo mal formado ou moléstias físicas ou psíquicas ou da criança, tais como a debilidade de sucção ou a presença de defeitos nos lábios ou abóbada palatina ${ }^{7}$. Contudo, observa-se que, nos últimos anos, cada vez mais a amamentação natural tem sido substituída pela artificial, tanto nos países menos desenvolvidos, como nos mais desenvolvidos, o que vem preocupando seriamente as autoridades sanitárias de todo o mundo ${ }^{5}$.

A tendência para a alimentação artificial, surge de uma combinação de fatores sociais e econômicos. $O$ amamentar é universal nas culturas tradicionais mas o processo de "modernização" leva a novas normas sociais em que a alimentação artificial se identifica com a idéia de sofisticação, conveniência e limpeza estética. As vezes, as novas normas vêm reforçadas pela prática e opinião de profissionais da saúde e pela hábil propaganda dos fabricantes de alimentos para bebês; esta última, com a forma e o conteúdo sumamente enganosos e carecendo às vezes, até de princípios éticos ${ }^{5}$.

Os fatores econômicos exercem sua influência sobre os processos sociais, pois cada dia mais as mulheres procuram trabalho fora de casa e não podem combinar o trabalho com a amamentação ao seio ${ }^{5}$. 
A tendência em utilizar a mamadeira, causada pelas pressões das mudanças sócio-econômicas, tem sido muito pronunciada e, potencialmente apresenta maiores riscos entre os pobres das áreas menos desenvolvidas e que crescem rapidamente. Os habitantes dos bairros pobres das zonas urbanas, são um grupo em desvantagem sobre o qual a confusão cultural e a pobreza fornecem forças para combater o costume tradicional de amamentar o bebê e aumentar os riscos da alimentação artificial ${ }^{5}$.

Muitos dos problemas de mudança de valores, que é um dos aspectos que parece que está influenciando o costume de não amamentar ao seio, talvez possa ser melhorado por meio de programas educativos junto às mães.

Qualquer programa educativo, entretanto, para ser bem sucedido, tem que ser baseado em cuidadoso planejamento e uma das fases mais importantes do planejamento é o diagnóstico adequado do problema e o conhecimento das características da população à qual se destina.

\section{FINALIDADES DO ESTUDO}

O presente trabalho visou estudar alguns aspectos referentes ao aleitamento materno em um grupo de mães. Teve como finalidade, não só proporcionar experiência aos alunos da Habilitação em Enfermagem de Saúde Pública da Escola de Enfermagem da USP, como estudar o assunto para subsidiar futuros programas educativos para populações semelhantes.

\section{METODOLOGIA}

A população estudada foi constituída por um grupo de mães que freqüentava um centro de saúde localizado na Região da Grande São Paulo.

A amostra constituiu-se de $10 \%$ de mães de crianças que tinham sido matriculadas durante 1 (um) ano, no referido serviço.

$O$ estudo foi realizado por docentes e alunos da EEUSP que estagiavam no centro de saúde já citado, no período de um mês e 
teve-se o cuidado de procurar não interferir e nem prejudicar a rotina de atendimento da clientela, nesse serviço.

A coleta de dados foi efetuada por meio de um formulário que foi previamente testado.

As mães entrevistadas foram as que levaram seus filhos para consulta médica no mês escolhido para estudo e cujas crianças não apresentavam problema de doença. Quando a mãe trouxe mais de um filho para a consulta, a entrevista sempre se referia ao mais novo.

\section{RESULTADOS E COMENTARIOS}

1. Condições de aleitamento das crianças

As condições de aleitamento das crianças cujas mães foram entrevistadas, encontram-se nas tabelas de 1 a 5 .

TABELA 1

Condições de aleitamento das crianças

\begin{tabular}{|c|c|c|}
\hline Condições & N. ${ }^{\circ}$ & $\%$ \\
\hline \multirow{5}{*}{ 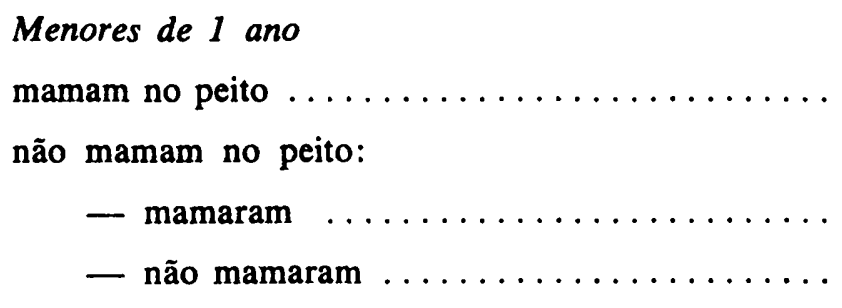 } & & \\
\hline & 45 & 36,6 \\
\hline & & \\
\hline & 43 & 35,0 \\
\hline & 35 & 28,4 \\
\hline Subtotal & 123 & 100,0 \\
\hline \multicolumn{3}{|l|}{ maiores de 1 ano } \\
\hline mamaram no peito & 21 & 63,6 \\
\hline não mamaram no peito & 12 & 36,4 \\
\hline Subtotal & 33 & 100,0 \\
\hline TOTAL $\ldots$. & 156 & 100,0 \\
\hline
\end{tabular}




\section{TABELA 2}

Crianças amamentadas e não amamentadas no peito

\begin{tabular}{|c|c|c|}
\hline Crianças & N. ${ }^{\circ}$ & $\%$ \\
\hline Amamentadas & 109 & 69,9 \\
\hline Não amamentadas & 47 & 30,1 \\
\hline TOTAL & 156 & $100,($ \\
\hline
\end{tabular}

TABELA 3

Motivos* pelos quais as crianças foram amamentadas ou ainda mamavam no peito

\section{Motivos}

N.o

$\%$

Mamaram enquanto as mães puderam dar (até o leite ficar "fraco", "secar", a criança aceitar, a mãe ter saúde ou não ter complicações de mamas ou outras)

E o melhor leite para a criança (os médicos e as enfermeiras nos hospitais ou centros de saúde dizem que é) $\ldots \ldots \ldots \ldots \ldots \ldots \ldots \ldots \ldots \ldots \ldots \ldots \ldots \ldots \ldots \ldots \ldots$

A mãe tinha muito leite $\ldots \ldots \ldots \ldots \ldots \ldots \ldots \ldots 16 \quad 12,6$

A mãe estava acostumada, achava natural ...... 7 7,5

Evitava doenças nas crianças $\ldots \ldots \ldots \ldots \ldots \ldots \ldots \quad 7 \quad 5,5$

Era mais fácil e/ou prático de ser administrado ... $3 \quad 3 \quad 2,4$

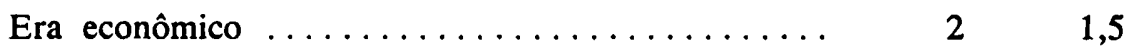

A criança não gostava de mamadeira $\ldots \ldots \ldots \ldots \ldots \quad 1 \quad 0,8$

A mãe não queria dar mamadeira $\ldots \ldots \ldots \ldots \ldots \quad 1 \quad 0,8$

TOTAL $\ldots \ldots \ldots \ldots \ldots \ldots \ldots \ldots \ldots \ldots \ldots \ldots \ldots \ldots \ldots \ldots$ 127* 100,0

* Algumas mães deram mais de um motivo. 


\section{TABELA 4}

Motivos pelos quais as crianças não tinham sido amamentadas

\begin{tabular}{|c|c|c|}
\hline Motivos & N. ${ }^{\circ}$ & $\%$ \\
\hline A mãe não teve leite, o leite era "fraco" ou insuficiente & 22 & 46,8 \\
\hline A criança "não aceitou" . . & 13 & 27,7 \\
\hline $\begin{array}{l}\text { A mãe teve problemas de mamas (infecções, trauma- } \\
\text { tismos) ou outras doenças } \ldots \ldots \ldots \ldots \ldots \ldots \ldots \ldots\end{array}$ & 6 & 12,8 \\
\hline A criança era prematura & 3 & 6,4 \\
\hline A mãe trabalhava fora $\ldots \ldots \ldots \ldots \ldots \ldots$ & 2 & 4,2 \\
\hline O filho era adotivo $\ldots \ldots \ldots \ldots \ldots \ldots \ldots \ldots$ & 1 & 2,1 \\
\hline
\end{tabular}

\section{TABELA 5}

Classificação dos motivos pelos quais as crianças não tinham sido amamentadas

\begin{tabular}{|c|c|c|}
\hline Motivos & N.o & $\%$ \\
\hline Ligados à mãe & 30 & 63,8 \\
\hline Ligados à criança $\ldots \ldots \ldots$ & 17 & 36,2 \\
\hline 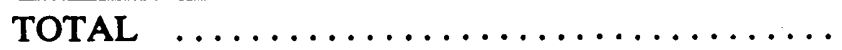 & 47 & 100,0 \\
\hline
\end{tabular}


Como se pode verificar pelos dados apresentados, das 156 crianças, cerca de dois terços $(69,9 \%)$ haviam sido amamentadas no peito, pelo menos em alguma época de suas vidas (Tabela 2).

Um estudo realizado por ROSENBURG 12 com crianças internadas em um hospital assistencial do Município de São Paulo, em 1972, mostrou preponderância do aleitamento artificial, em relação a todos os tipos $(91,97 \%)$.

Comparando-se esses dados, com os resultados do nosso trabalho, podemos deduzir que o aleitamento materno foi mais freqüente no grupo de crianças freqüentadoras do centro de saúde em questão, do que entre as crianças internadas no hospital onde foi realizado o trabalho de ROSENBURG ${ }^{12}$. Por outro lado, o aleitamento materno foi muito mais freqüente nas crianças aparentemente sadias, que freqüentavam o centro de saúde do que nas doentes internadas no hospital já referido.

$\mathrm{Na}$ Inglaterra, PROTERO 10 investigando a respeito do assunto, verificou que somente $41 \%$ das mães amamentaram no seio as suas crianças, por períodos variados, além dos 6 meses; somente $33 \%$ do total foi além das quatro primeiras semanas.

Além desses, muitos autores $3,4,6,8,14$, ainda em vários países, têm alertado em seus trabalhos, que há um declínio no hábito de amamentar no seio e uma substituição, cada vez maior, pela alimentação com leites artificiais.

No Chile ${ }^{8}$ em algumas áreas, a amamentação ao seio diminuiu nesses últimos 30 anos, de $95 \%$, para $16 \%$.

Quanto aos motivos pelos quais as crianças haviam mamado ou ainda mamavam no peito (Tabela 3), segundo as mães, os mais freqüentes referiam-se ao fato dela poder amamentar ou a criança aceitar $(44,1 \%)$, seguido da indicação de ser, o leite materno, o melhor leite para as crianças, segundo os "especialistas" (26,8\%).

LARKIN ${ }^{6}$, em uma pesquisa realizada em 1968, verificou que $97 \%$ das mulheres informaram que a amamentação no seio era uma prática boa acrescentando muitas vezes "se for possível".

Quanto às crianças de nosso estudo, as que nunca haviam sido amamentadas $(30,1 \%)$, o motivo principal $(46,8 \%)$ refe- 
ria-se à escassez de leite ou "leite fraco", que foi o termo mais utilizado pelas mães.

LARKNN ${ }^{\circ}$, em seu trabalho, relata que $21 \%$ de mães entrevistadas, não amamentavam ao peito porque consideravam a mamadeira mais confortável que o aleitamento no peito. Por outro lado, o aleitamento natural foi associado aos hábitos "antigos" ou aos "velhos tempos".

MONCKERBERG ${ }^{8}$, diz que, no Chile, algumas mulheres receiam que a amamentação possa torná-las menos atrativas, afetando a forma e tamanho do busto mas que, nas zonas rurais, isto não é assim e é comum encontrar mães amamentando em público, como acontece nas áreas rurais em nosso meio.

Classificando os motivos pelos quais essas crianças não tinham sido amamentadas, verificou-se que, segundo as informações, mais da metade deles $(63,8 \%)$ estavam ligados a problemas das mães e não das crianças e, muitos deles, passíveis de serem resolvidos com um atendimento pré-natal adequado e que incluísse orientação eficiente sobre a importância da amamentação e prevenção de problemas com os seios.

tificial

2. Opiniões das mães sobre o aleitamento natural $e$ ar-

As opiniões das mães sobre o aleitamento natural e artificial encontram-se nas tabelas 6 a 13.

\section{TABELA 6}

Opinião das mães sobre qual o melhor leite a ser dado para crianças menores de 1 ano

\begin{tabular}{|c|c|c|}
\hline Opinião sobre o melhor leite & N.o & $\%$ \\
\hline de peito $\ldots . . . \ldots$. & 113 & 72,4 \\
\hline$\ldots \ldots \ldots \ldots \ldots \ldots \ldots$ & 40 & 270 \\
\hline$\ldots \ldots \ldots \ldots \ldots \ldots$ & 2 & 27,0 \\
\hline 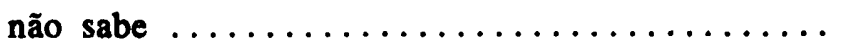 & 1 & 0,6 \\
\hline TOTAL & 156 & 100,0 \\
\hline
\end{tabular}




\section{TABELA 7}

Motivos porque as mães consideram o leite de peito o melhor para crianças menores de 1 ano

\begin{tabular}{lll}
\hline Motivos & N. & $\%$ \\
\hline
\end{tabular}

Evita doenças, outros problemas e não faz mal à saúde

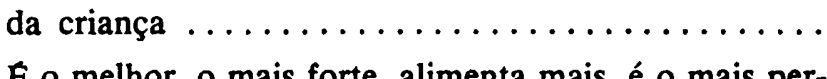

E o melhor, o mais forte, alimenta mais, é o mais perfeito ou ideal e não pode ser substituído ........ 61

E mais higiênico ou sadio, não estraga ou azeda ... $78 \quad 38,0$

E mais fácil de ser usado $\ldots \ldots \ldots \ldots \ldots \ldots \ldots$

As pessoas e as publicações dizem que é o melhor

Tem mais vitaminas e sais minerais $\ldots \ldots \ldots \ldots$

E mais puro e mais natural $\ldots \ldots \ldots \ldots \ldots \ldots$

E o melhor, se a mãe tem saúde $\ldots \ldots \ldots \ldots \ldots$

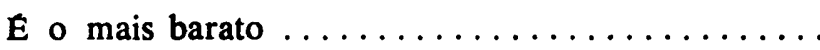

E bom até certa idade, depois fica fraco ....... $3 \quad 1,5$

O médico disse que é o melhor ........... $3 \quad 1,5$

"E o sangue da mãe"................. 110

"A dosagem e temperatura é sempre igual" ....... 10,5

Não sabe ou não respondeu $\ldots \ldots \ldots \ldots \ldots \ldots \ldots .110 ., 15$

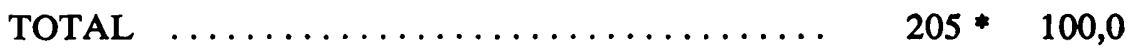

- Algumas mães deram mais de um motivo. 


\section{TABELA 8}

Motivos porque as mães consideram o leite em pó o melhor para crianças menores de 1 ano

\begin{tabular}{|c|c|c|}
\hline Motivos & N. ${ }^{\circ}$ & $\%$ \\
\hline $\begin{array}{l}\text { E o mais forte, tem mais vitaminas, sustenta mais, } \\
\text { é o mais seguro, evita doenças } \ldots \ldots \ldots \ldots \ldots \ldots\end{array}$ & 25 & 44,6 \\
\hline E o mais prático e o que rende mais $\ldots \ldots \ldots \ldots$ & 9 & 16,1 \\
\hline Já está acostumada $\ldots \ldots \ldots \ldots \ldots \ldots \ldots \ldots$ & 4 & 7,1 \\
\hline Tem mais confiança $\ldots \ldots \ldots \ldots \ldots \ldots \ldots$ & 4 & 7,1 \\
\hline "O leite de bar dá diarréia ou a criança não aceita" & 3 & 5,4 \\
\hline A criança engorda mais e a gente vê quanto ela toma & 2 & 3,6 \\
\hline O leite de peito é mais fraco $\ldots \ldots \ldots \ldots \ldots \ldots$ & 2 & 3,6 \\
\hline E mais barato $\ldots \ldots \ldots \ldots \ldots \ldots \ldots \ldots \ldots$ & 1 & 1,8 \\
\hline Não sabe ou não respondeu $\ldots \ldots \ldots \ldots \ldots \ldots$ & 6 & 10,7 \\
\hline
\end{tabular}

- Algumas mães apresentaram mais de um motivo.

\section{TABELA 9}

Motivos porque as mães consideram o leite de vaca o melhor para crianças menores de 1 ano

Motivos N.

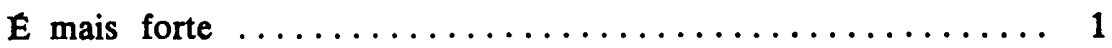

E o mais prático e não precisa preparar $\ldots \ldots \ldots \ldots \ldots \ldots \ldots 1$

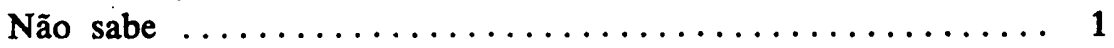

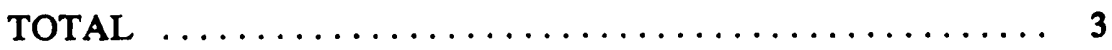


TABELA 10

Classificação das opiniões * das mães sobre o leite de peito

Opiniões

N. ${ }^{\circ}$

$\%$

Favoráveis

E o melhor porque é o mais completo, mais forte, adequado, nutritivo, passa direto da mãe para a criança, quem tem sempre deve dar .............

Evita doenças e outros problemas ........... $104 \quad 48,2$

6128,3

E o mais higiênico, mais fresco, mais saudável e tep temperatura adequada $17 \quad 7,9$

E o mais prático 146,5

Todos dizem que é bom $\ldots \ldots \ldots \ldots \ldots \ldots \ldots \ldots \quad 8 \quad 8 \ldots \ldots$

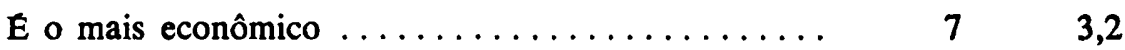

E como remédio e para a criança doente é o único

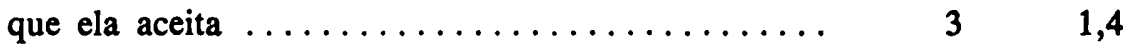

E o mais recomendado pelo médico $\ldots \ldots \ldots \ldots \ldots \quad 2 \quad 0,9$

Subtotal $\ldots \ldots \ldots \ldots \ldots \ldots \ldots \ldots \ldots \ldots 216 \quad 100,0$

Favoráveis ou desfavoráveis dependendo da ocasião

E bom se a mãe tem saúde e a criança se der bem $11 \quad 84,61$

E bom se a mãe não trabalha fora $\ldots \ldots \ldots \ldots \ldots \quad 2 \quad 15,39$

Subtotal

13100,0

Desfavoráveis

Não é bom porque precisa ser completado, não sai na hora que se quer, prende a mãe em casa, rouba tempo da mãe, é fraco, tem gosto ruim e seca com facilidade $\ldots \ldots \ldots \ldots \ldots \ldots \ldots \ldots \ldots \ldots \ldots, 11 \quad 91,67$

Se a mãe tem doença, passa para o filho ....... $1 \quad 8,33$

Subtotal

12100,0

TOTAL

- Algumas mães deram mais de uma opinião. 
TABELA 11

Opiniões * das mães sobre o leite de peito

\begin{tabular}{|c|c|c|}
\hline Opiniões & N.'o & $\%$ \\
\hline Favoráveis $\ldots \ldots \ldots \ldots \ldots \ldots$ & 216 & 89,6 \\
\hline Favoráveis ou desfavoráveis dependendo da ocasião & 13 & 5,4 \\
\hline Desfavoráveis $\ldots \ldots \ldots \ldots \ldots \ldots \ldots \ldots \ldots \ldots \ldots \ldots \ldots \ldots \ldots$ & 12 & 5,0 \\
\hline
\end{tabular}

* Algumas mães deram mais de uma opinião englobadas em favoráveis, favoráveis ou desfavoráveis dependendo da ocasião e desfavoráveis. 
TABELA 12

Classificação das opiniões * das mães sobre o leite em pó

Opiniões

N.o $\%$

Favoráveis

E o melhor porque sustenta mais, é mais seguro ou puro, rende mais, é mais completo, é mais forte, pode misturar com farinha ou aveia .............. E o mais prático para se preparar, pode ser usado de várias maneiras, não há perigo de faltar ou estragar Não faz mal à criança "Confia mais" $86 \quad 81,2$

E leite de vaca só que em pó $11 \quad 10,4$

E melhor porque recebe no posto $\ldots \ldots \ldots \ldots \ldots$

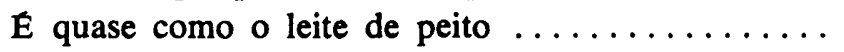

Subtotal

$106 \quad 100,0$

Desfavoráveis

Não é igual ao peito e só serve para substituí-lo porque tem substâncias prejudiciais, é mais fraco, ocasiona prisão de ventre e a criança regorgita muito $43 \quad 82,7$ E caro, difícil de ser encontrado e não é prático porque precisa ser engrossado, é difícil de ser preparado

Subtotal $\ldots \ldots \ldots \ldots \ldots \ldots \ldots \ldots$

$52,100,0$

Favoráveis ou desfavoráveis dependendo da ocasiāo Depende da marca para ser bom . ..............

E bom se a criança aceita e não lhe faz mal ..... Serve para substituir o leite da mãe $\ldots \ldots \ldots \ldots \ldots .48 \quad 18,2$ E bom só se for preparado adequadamente ...... $6 \quad 13,6$ Depende da idade da criança e do tipo de leite e da indicação do médico .................. $2 \quad 4,5$ $E$ bom desde que não esteja estragado $\ldots \ldots \ldots \ldots \quad 1 \quad 2,2$

\begin{tabular}{rrr}
\hline Subtotal $\ldots \ldots \ldots \ldots \ldots \ldots \ldots \ldots \ldots \ldots \ldots \ldots \ldots$ & 44 & 100,0 \\
\hline TOTAL $\ldots \ldots \ldots \ldots \ldots \ldots \ldots \ldots \ldots \ldots \ldots \ldots \ldots \ldots$ & 202 & - \\
\hline
\end{tabular}

* Algumas mães deram mais de uma opinjão. 
TABELA 13

Opiniões * das mães sobre o leite em pó

\begin{tabular}{|c|c|c|}
\hline Opiniões & N.o & $\%$ \\
\hline Favoráveis & 108 & 57,8 \\
\hline Desfavoráveis & 52 & 27,8 \\
\hline Favoráveis ou desfavoráveis dependendo da ocasião & 27 & 14,4 \\
\hline TOTAL & 187 & 100,0 \\
\hline
\end{tabular}

* Algumas mães deram mais de uma opinião.

Para a maioria das mães $(72,4 \%)$, o melhor leite a ser dado para crianças menores de 1 ano, foi o "leite de peito" (Tabela 6), embora $27,0 \%$ considerasse o leite de vaca de forma natural ou em pó.

Embora fosse uma minoria, o grupo de mães que considerou o aleitamento artificial melhor que o natural, provavelmente suas crianças serão aquelas a terem os problemas intestinais tão comuns em nosso meio e, em termos de prevenção, não deverão ser abandonadas.

Os motivos pelos quais as mães consideram o leite de peito melhor para crianças menores de 1 ano (Tabela 7), está ligado principalmente ao fato delas considerarem, em primeiro lugar $(38,0 \%)$, que o mesmo "evita doenças e não faz mal à saúde da criança" e, em segundo lugar, "porque é o melhor, o mais forte, alimenta mais, é o mais perfeito ou ideal e não pode ser substituído".

Várias causas, segundo autores ${ }^{3,12}$, podem concorrer para que as mães passem a considerar o leite de vaca, melhor que o humano, dentre elas, os altos propósitos dos serviços de saúde. Assim na China, em áreas rurais, nas quais os serviços de saúde penetram, há uma súbita redução na amamentação materna, enquanto em outras áreas onde não havia tais serviços, o tradicional hábito de prolongar a amamentação persiste. Isto porque, nos hospitais e ambulatórios, às vezes, a alimentação artificial chega até a ser promovida. Em nosso meio, por exemplo, muitas vezes encontramos mães que ao terem alta da maternidade já saem com uma "receita de mamadeira" para completar uma possível escassez de leite. 
Como alguns organismos internacionais ${ }^{8}$, como a FAO, OMS e UNICEF, têm enfatizado, as últimas duas décadas foram caracterizadas pela expansão de atividades de firmas de alimentos infantis, nos países menos desenvolvidos, com campanhas competitivas de anúncios que promovem "status" e fazem com que os leites preparados sejam distribuídos em comunidades não orientadas. Os serviços de saúde, por outro lado, são persuadidos a agir como agentes gratuitos, inconscientes, ao aceitarem amostras grátis, cartazes e outro tipo de publicidade.

Segundo MONCKENBERG ${ }^{8}$, o desmame precoce nos países subdesenvolvidos é uma das importantes causas da subnutrição durante o primeiro ano de vida e, quando as condiçōes sócio-econômicas são insatisfatórias, a distribuição de leite gratuita não impede a má nutrição.

O uso do leite em pó já assumiu, nas camadas mais carentes da população, dimensões consideráveis por vários motivos: propaganda, industrialização, urbanização, hábito já estabelecido de se fazer distribuição gratuita de leite em pó indiscriminadamente em alguns serviços de saúde, etc. A oferta de uma lata de leite em pó à mãe pobre pode resultar num estímulo para o abandono da alimentação natural.

Em relação a esse tópico, $\mathrm{CHASE}^{3}$ diz que "quando quotas suplementares de leite são distribuídas às crianças, a frequiência da alimentação ao peito diminui. Além disso, o suplemento é dado em grande parte, às crianças mais velhas, levando a mais nova à subnutrição, numa idade mais precoce".

No Chile ${ }^{8}$, o programa de distribuição gratuita de leite em pó, foi uma arma de dois gumes porque enquanto pretendeu corrigir a desnutrição no primeiro ano de vida, ajudou a promover a diminuição da incidência e duração da amamentação, agravando assim o problema.

Ainda, a respeito das opiniões das mães sobre os vários tipos de leite (Tabelas 10,11, 12 e 13), verificou-se o seguinte:

- quanto ao leite de peito, $89,6 \%$, deram opiniões favoráveis e a maioria respondeu que "é o mais forte e nutritivo"; uma pequena parcela $(5,0 \%)$ deu opiniões desfavoráveis e a maioria destas, por razões relativas à possibilidade de escassez; 
- quanto ao leite em pó, $57,8 \%$ foram favoráveis pelos mesmos motivos apresentados para o leite humano ("sustenta mais") e $27,8 \%$ consideradas desfavoráveis porque "ele só serve como substituto".

Vale a pena ressaltar, ainda, em relação a essas opiniōes, que algumas mães que foram favoráveis ao leite em pó $(81,2 \%)$, foi devido ao fato do mesmo poder "ser misturado com farinha ou aveia", opinião esta que vem de encontro ao que se observa na prática, isto é, a idéia que algumas mães têm de que é necessário "engrossar" o leite para a criança aceitá-lo melhor.

Ainda, com relação às opiniões, verificou-se que, em relação ao leite humano, as opiniões favoráveis foram em porcentagem muito maior que as opiniões favoráveis em relação ao leite em pó e que a idéia do primeiro ser "o mais forte", vem mostrar algum conhecimento sobre as vantagens deste em relação ao segundo.

Quanto à idade ideal para o desmame (Tabelas 14 e 15, a seguir), a maioria das mães $(43,6 \%)$ preconizou o desmame tardio (depois de 12 meses), embora uma boa parcela $(23,7 \%) 0$ indicasse antes dos 9 meses. Essas opiniões levam a concluir que algumas mães não sabiam a época ideal para o desmame, embora soubessem que depois de uma certa idade, unicamente o leite materno, já não sustentaria mais a criança. Interessante notar, com relação a esses dados que, embora com uma frequiência pequena, houve alguns motivos ligados ao aspecto cultural, como o fato de "ser feio" ou "evitar a gravidez".

\section{TABELA 14}

Opinião das mães sobre a idade para o desmame

\begin{tabular}{|c|c|c|c|}
\hline Idade em meses & N.o & $\%$ & \\
\hline Antes dos 3 meses $\ldots$ & 2 & $1,3)$ & \\
\hline dos $3 \longmapsto 6$ meses & 23 & 14,7 & 23,7 \\
\hline dos $6 \vdash-9$ meses & 12 & 7,7 & \\
\hline $\operatorname{dos} 9 \longmapsto 12$ meses $\ldots \ldots \ldots \ldots \ldots$ & 41 & $26,3^{-}$ & \\
\hline dos 12 meses em diante $\ldots \ldots \ldots \ldots \ldots$ & 68 & 43,6 & \\
\hline Não sabe $\ldots \ldots \ldots \ldots \ldots \ldots \ldots \ldots$ & 10 & 6,4 & \\
\hline COTAL & 156 & 100,0 & \\
\hline
\end{tabular}


TABEEA 15

Motivos* apontados pelas mães para o desmame na idade indicada por elas

\begin{tabular}{|c|c|c|}
\hline Motivos & N. ${ }^{\circ}$ & $\%$ \\
\hline \multicolumn{3}{|l|}{$\begin{array}{l}\text { Porque depois de certa idade a criança já come outros } \\
\text { alimentos. e o leite é só complemento; já não sustenta }\end{array}$} \\
\hline mais porque é fraco $\ldots \ldots \ldots \ldots \ldots \ldots \ldots$ & 48 & 27,3 \\
\hline Porque é o melhor leite até certa idade, a criança & & \\
\hline fica mais forte, sem doenças ou problemas intestinais & 52 & 29,5 \\
\hline $\begin{array}{l}\text { Porque depois de certa idade, a mãe fica fraca, a } \\
\text { criança mal acostumada e é feio, porque ela já co- } \\
\text { meça a entender, já morde o mamilo e machuca a }\end{array}$ & & \\
\hline mãe e a mãe fica muito ocupada $\ldots \ldots \ldots \ldots \ldots$ & 30 & 17,1 \\
\hline $\begin{array}{l}\text { Porque se deve dar até quando a criança quiser ou } \\
\text { aceitar } \quad \ldots \ldots \ldots \ldots \ldots \ldots \ldots \ldots \ldots \ldots \ldots\end{array}$ & 19 & 10,8 \\
\hline Porque se desmamar antes, não evita a gravidez .. & 8 & 4,5 \\
\hline Porque tem pena de desperdiçar $\ldots \ldots \ldots \ldots \ldots$ & 3 & 1,7 \\
\hline Porque minha mãe o fez assim $\ldots \ldots \ldots \ldots \ldots$ & 2 & 1,1 \\
\hline Porque quanto mais cedo mais fácil ... & 2 & 1,1 \\
\hline Porque mais econômico até certa idade .... & 1 & 0,6 \\
\hline Porque depois de certa idade "dá lombrigas" ..... & 1 & 0,6 \\
\hline Porque se desmamar mais tarde a criança pode morrer & 1 & 0,6 \\
\hline Porque o leite em pó prende $o$ intestino $\ldots \ldots \ldots$ & 1 & 0,6 \\
\hline Porque é uma boa idade $\ldots \ldots \ldots \ldots \ldots \ldots$ & 1 & 0,6 \\
\hline Porque gosta $\ldots \ldots \ldots \ldots \ldots \ldots \ldots \ldots \ldots$ & 1 & 0,6 \\
\hline Não sabe $\ldots \ldots \ldots \ldots \ldots \ldots \ldots \ldots \ldots \ldots$ & 6 & 3,4 \\
\hline TA & 176 & 100,0 \\
\hline
\end{tabular}

- Algumas mães deram mais de um motivo. 


\section{CONCLUSOES E RECOMENDAÇOES}

As condições de aleitamento das crianças estudadas, não foram muito ruins, pois mais da metade havia recebido, em alguma época de suas vidas, mesmo que por pouco tempo, o "leite de peito", e esse, na opinião de $\mathbf{7 2 , 4 \%}$ das mães entrevistadas, era o melhor para ser dado para crianças menores de 1 ano de idade.

Embora o leite em pó ou "de vaca" tenha sido considerado por uma minoria $(27,0 \%)$ o melhor leite a ser dado para crianças menores de 1 ano, não há razão para que se considere as mães razoavelmente orientadas e, para que o aleitamento materno seja cada vez mais incentivado, há necessidade de ser feito um trabalho educativo cada vez mais intenso.

De um modo geral, médicos e enfermeiras estão cientes das numerosas vantagens da alimentação no peito. Referências a respeito, encontram-se na literatura pediátrica e psiquiátrica. $O$ problema básico ${ }^{1}$, entretanto, é que nem sempre eles encorajam o aleitamento no seio. Porque os estudantes desconhecem os princípios básicos desta "arte feminina", e o pior de tudo, porque os bem intencionados, simpatizantes do aleitamento materno, estão entre os primeiros a "colocar o nenê na mamadeira?". Parece que isto acontece porque desconhecem principios fundamentais de anatomia e fisiologia da mama e a sua função. Se eles conhecessem, coordenariam seus esforços para prover uma lactação natural.

O sucesso da amamentação ao seio depende de muitas variáveis interelacionadas: uma motivação forte da mãe e do pai, cooperação, saúde, força de sucção da criança e a atitude de compreensão, conhecimento e encorajamento do profissional.

De acordo com essas considerações, talvez o ponto mais importante para conseguir fomentar o aleitamento materno em uma comunidade, seja preparar e motivar, em primeiro lugar, os profissionais de saúde e não as mães, embora em nosso estudo, algumas mães não demonstraram conhecimentos suficientes em relação ao aleitamento natural ou artificial.

O ensino das futuras mães pode ter início; não só nos serviços de saúde, mas na família; nos serviços de saúde, descie o perfodo 
pré-natal e na comunidade, por meio de campanhas de esclarecimento público.

Quanto ao problema da mulher que trabalha, o qual não apareceu como causa significante de desmame precoce, no grupo estudado, há necessidade de cumprimento de legislação já existente sobre os direitos da mulher, durante o ciclo grávido puerperal e a criação de condições e serviços assistenciais à nutriz, como creches junto aos locais de trabalho para permitir e incentivar a amamentação.

RAMOS NETTO, M. O. et al. - A brest-feeding study. Rev. Esc. Enf. USP, $12(2): 77-100,1978$.

As an introduction the authors consider the advantages of breast-feeding, describing the social-economic causes which are influencing, the abandonment of this practice in the world. Following this they describe and comment on the results of a research project carried out with a group of mothers, which had as its objective to study some aspects relative to breast-feeding children. 


\section{REFERENCIAS BIBLIOGRAFICAS}

1. APPLEBAUM, R. M. - The modern Management of successful breast feeding. Pediatr. Clin. N. Amer., 17:203-25, feb., 1970.

2. BRASIL - FUNDAÇÃO IBGE - Anuário Estatistico do Brasil. Rio de Janeiro, IBGE, 1972.

3. CHASE, H. \& MAR'IIN, H. P. - Under-nutrition and development. New Eng. J. Med., 282:933-9, 1970.

4. DUGDALE, A. E. - The effect of the type of feeding on weight gain and illnesses in infants. Br. J. Nutr., 26:423-32, 1971.

5. GRAY, R. H. - El amamentar y la salud de la madre y del niño. Bol. Med. de IPPF, 9(6), dez. 1975.

6. LARKIN, F. A. - Pattern of weaning in Dominica. West Indian Med. J., 20:229-36, 1971.

7. MARCONDES, E. \& ALCÂNTARA, P. - Pediatria Básica. São Paulo, Sarvier, 1974.

8. MONCKEBERG, B. F. - Infant feeding and weaning practice the problem as it exists in developing countries. Aust. Paediatr. J., 9:1-70, 1973.

9. NOGUEIRA, M. J. de C. - Caracteristicas de uma favela da Região da Grande São Paulo. Rev. Esc. Enf. USP, 2:230-48, 1976.

10. PROTERO, R. - Attitudes to breast-feeding. British Med. J., London, Saturday, 19 April, 1969.

11. PUFFER, R. K. e SERRANO, E. V. - Caracteristicas de la mortalidad en la ninez. Washington, OPAS, 1973. Publicacion cientifica n. ${ }^{\circ} 262$.

12. ROSENBURG, O. - Aleitamento no primeiro ano de vida de crianças internadas em hospital assistencial do Município de São Paulo, Brasil. Rev. Saúde Publ., 7:381-8, 1973. 
13. SAN MARTIN, H. - Salud y enfermedad. México, Prensa Medica Mexicana, 1968.

14. UNGERRAGA, O. et al. - Alimentación Materna en problaciones de distinto nivel socio-económico y cultural. Rev. Chilena de Pediat., 38:356-9., 1967. 